\section{Anabolic Skeletal Therapy for Osteoporosis}

\begin{abstract}
Antiresorptive agents for osteoporosis are a cornerstone of therapy, but anabolic drugs have recently widened our therapeutic options. By directly stimulating bone formation, anabolic agents reduce fracture incidence by improving bone qualities besides increasing bone mass. In this article, we review the role of anabolic treatment for osteoporosis. The only anabolic agent currently approved in the United States for osteoporosis, teriparatide (recombinant human parathyroid hormone(1-34)), has clearly emerged as a major approach to selected patients with osteoporosis. Teriparatide increases bone density and bone turnover, improves microarchitecture, and changes bone size. The incidence of vertebral and nonvertebral fractures is reduced. Teriparatide is approved for both postmenopausal women and men with osteoporosis who are at high risk for fracture. Other potential anabolic therapies for osteoporosis, including other forms of parathyroid hormone, strontium ranelate, growth hormone, and insulin-like growth factor-1, are also reviewed in this article.
\end{abstract} (Arq Bras Endocrinol Metab 2006;50/4:745-754)

Keywords: Anabolic agents; Bone quality; Bone mass; Osteoporosis; Teriparatide; Fracture risk

\section{RESUMO}

\section{Tratamento Anabólico Ósseo para Osteoporose.}

Os agentes anti-reabsortivos são as drogas mais usadas no tratamento da osteoporose, porém os anabólicos recentemente ampliaram nossas opções terapêuticas. Por estimular diretamente a formação, os agentes anabólicos reduzem a incidência de fraturas por melhorar a qualidade óssea, além do aumento da massa óssea. Neste artigo, nós revisaremos o papel do tratamento anabólico para a osteoporose. O único agente anabólico, atualmente aprovado nos Estados Unidos, é o teriparatida (hormônio paratiroidiano recombinante humano), o qual tem sido considerado como a principal abordagem em pacientes selecionados. $O$ teriparatida aumenta a densidade mineral óssea e o turnover ósseo, melhorando a microarquitetura, e altera o tamanho do osso. A incidência de fraturas vertebrais e não vertebrais é reduzida. O teriparatida é aprovado tanto para mulheres na pós-menopausa quanto para homens com osteoporose que apresentem alto risco para fraturas. Outras terapias anabólicas potenciais para a osteoporose incluem outras formas de hormônio da paratiróide, ranelato de estrôncio, hormônio de crescimento e IGF1 (insulin-like growth factor-1), e serão revisados neste artigo. (Arq Bras Endocrinol Metab 2006;50/4:745-754)

Descritores: Agentes anabolizantes; Qualidade óssea; Massa óssea; Osteoporose; Teriparatida; Risco de fraturas

\author{
Monica Givotra \\ Misbaela R. Rubin \\ Jobn P. Bilezikian
}

Department of Medicine ( $M G$, $M R R$ \& JPB) and Pharmacology (JPB), College of Physicians and Surgeons, Columbia University, New York, NY, USA.
Received in 05/10/06 Accepted in 05/20/06 
A NABOLIC AGENTS REPRESENT an important new advance in the therapy of osteoporosis. Until recently, antiresorptive agents were the exclusive pharmacological approach to this disease. They are covered in other articles in this supplement. The anabolic skeletal agents, in contrast to the antiresorptive drugs, influence processes associated with bone formation. By stimulating bone formation to a greater extent and earlier than bone resorption, anabolic agents have the potential to positively affect a number of skeletal properties besides bone density. These include bone size and microarchitecture. They thus have the potential to reconstruct the skeleton, an endpoint not shared by any of the antiresorptives (1). The anabolic agents to be discussed in this review include teriparatide [parathyroid hormone(1-34)], other forms of parathyroid hormone, strontium ranelate, and growth hormone/insulin-like growth factor- 1 .

\section{PARATHYROID HORMONE AS AN ANABOLIC AGENT}

In primary hyperparathyroidism (PHPT), a disorder of chronic, continuous secretion of excess parathyroid hormone $(\mathrm{PTH})$, catabolic effects, primarily at cortical sites such as the distal $1 / 3$ radius, is common. Nevertheless, even in this disorder of chronic PTH secretion, a key property of intermittent PTH administration, namely salutary effects at the cancellous skeleton such as the lumbar spine, can be seen (2). The clinical clue to the utility of PTH as an anabolic skeletal agent came with the recognition that its anabolic potential is seen much more clearly with low dose, intermittent administration. PTH is currently available in many countries as the recombinant human PTH(1-34) fragment known as teriparatide. The full-length molecule, human recombinant PTH(1-84), has been approved for use in some European countries and is under investigation at this time in the United States. Teriparatide leads to a rapid increase in bone formation markers followed sometime thereafter by increases in bone resorption markers. If these markers reflect physiological events, PTH likely initially stimulates processes associated with bone formation (bone modeling) and only later promotes those associated with bone remodeling in which bone resorption predominates. This sequence of events has led to the concept of the "anabolic window," a period of time when the actions of PTH are maximally anabolic (3) (figure 1).

The beneficial effects of teriparatide on bone qualities such as bone density, microarchitecture and bone geometry are seen in the cancellous skeleton (4). At a cortical skeletal site, such as the distal $1 / 3$ radius, PTH typically does not increase bone density. In fact, there may be a small decline in BMD in association with an increase in cortical porosity. However, this does not translate into decreased bone strength because the increased porosity occurs only in the inner one third of bone, where the mechanical effect

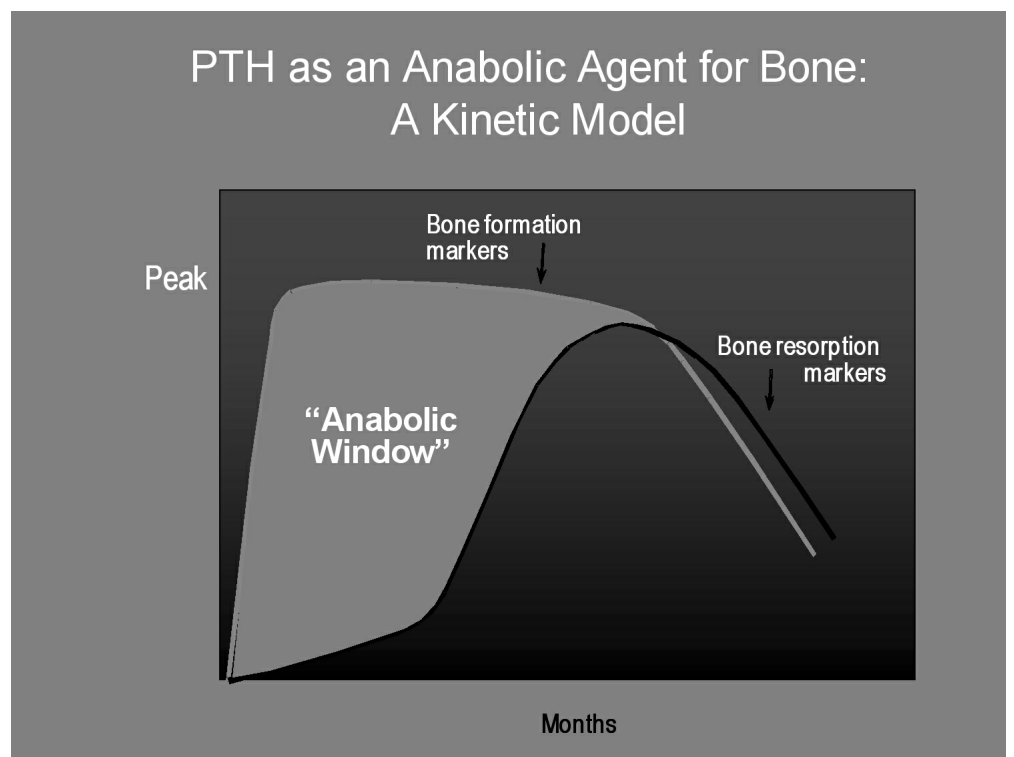

Figure 1. The Anabolic Window. Based upon the difference in kinetics of changes between bone formation and bone resorption markers, an "anabolic window" is formed during which the actions of parathyroid hormone are believed to be maximally anabolic. 
is minimal. Even more importantly, other salutary effects of teriparatide at cortical bone, such as changes in bone geometry and microarchitecture, more than compensate for any increase in cortical porosity (5). PTH stimulates periosteal apposition, which leads to increases in cortical area, cortical thickness, and an overall increase in cross-sectional area $(5,6)$. Moreover, microarchitectural changes due to teriparatide are evident at the cortical sites such as the distal $1 / 3$ radius as well. These geometrical and microarchitectural changes strengthen cortical bone despite the small reduction in bone density (7).

\section{INDICATIONS FOR TERIPARATIDE}

Teriparatide is used in postmenopausal women and men with osteoporosis who are at high risk for fracture. To help select patients for teriparatide, useful guidelines have been published (1). Patients who have already sustained an osteoporotic fracture are among the highest risk group because the likelihood of sustaining another fracture is very high (8). The T-score itself, even without an osteoporotic fracture, can confer high risk, especially if the T-score is very low (i.e. < -3.0). Patient age is also important as for any T-score, the older the patient the greater the risk. Other potential candidates for teriparatide are patients for whom one might consider a bisphosphonate but who cannot tolerate the drug or who are non-compliant. In addition, patients who fracture while on antiresorptive therapy could be considered to be at high risk and thus candidates for teriparatide. In most countries, teriparatide is approved for a limited period of time, 18-24 months.

\section{TERIPARATIDE AS SINGLE IN POSTMENOPAUSAL OSTEOPOROSIS}

In the randomized, double-blind, pivotal clinical trial of, Neer et al., women with severe osteoporosis were treated with subcutaneous injections of placebo, 20 or $40 \mu \mathrm{g}$ of teriparatide. The average number of fragility fractures per patient was over 2 , clearly defining this group as at high risk (9). Over a follow-up period of 21 months, BMD increased by an average of $10-14 \%$. Femoral neck BMD also improved, but more slowly and to a smaller extent (approximately 3\%) in comparison to the lumbar spine. At $20 \mu \mathrm{g}$ of teriparatide, BMD did not change at the distal radius. The most important findings of the teriparatide trial by Neer et al. were reductions in new ver- tebral fractures by $65 \%$ at the 20 . The overall incidence of new nonvertebral fractures was reduced by $35 \%$ at the $20 \mu \mathrm{g}$ dose. Hip fracture incidence was not analyzed separately because the study was not sufficiently powered to examine this endpoint. By post-hoc analysis, the reduction in fracture incidence due to teriparatide was not related to the number, severity, or site of previous fractures (10). Further post-hoc analysis of this cohort demonstrated that the fracture risk reduction was largely independent of age and initial BMD (11). In an observational cohort from this trial, fracture reduction was sustained for up to 30 months after teriparatide discontinuation, although many individuals in the original and treatment groups received bisphosphonate therapy during this follow-up period (12).

\section{PTH (1-84) IN POSTMENOPAUSAL OSTEOPOROSIS}

PTH(1-84) has been the object of a limited number of studies. In a preliminary clinical trial, preparatory to the definitive clinical trial, subjects were administered placebo, or 1 of 3 doses of PTH(1-84): 50, 75, or $100 \mu \mathrm{g}$ for 12 months (13). There were time- and dose-related increases in lumbar spine BMD. Similar to the teriparatide studies, bone turnover markers rose quickly. Histomorphometric analyses of bone biopsy specimens confirm an anabolic response to $\mathrm{PTH}(1-84)$ with an increase in bone formation and improvements in cancellous architecture (14). In contrast to the study by Neer et al. in which the average number of fragility fractures per study subject was $>2$, the incidence of baseline fragility fractures in the phase III PTH(1-84) study was only $19 \%$. Nevertheless, a reduction in new vertebral fracture incidence was seen with $\mathrm{PTH}(1-84)$ in women both with and without prior vertebral fractures (15).

\section{TERIPARATIDE IN MEN WITH OSTEOPOROSIS}

In the first randomized, controlled trial of teriparatide in men, Kurland et al. randomized 23 men to 400 $\mathrm{U} /$ day of teriparatide (equivalent to $25 \mu \mathrm{g} /$ day) or placebo for 18 months in a double-blinded protocol (16). The men who received teriparatide demonstrated an impressive $13.5 \%$ increase in lumbar spine bone density. Hip BMD increased significantly but more slowly and to a smaller extent in comparison to the lumbar spine. Cortical bone density at the distal radius did not change as compared to placebo. Bone turnover markers rose quickly and substantially in the men treated with teriparatide, with bone formation 
markers rising and peaking earlier than bone resorption markers. In a larger trial of 437 men that was the counterpart of the pivotal trial of Neer et al. in postmenopausal women, Orwoll et al. (17) followed a protocol that was essentially identical to the study of Neer et al. BMD increased significantly in the $20 \mu \mathrm{g}$ treatment group by $5.9 \%$ at the lumbar spine and by $1.5 \%$ at the femoral neck. These increases were independent of gonadal status. The magnitude and time course of BMD increases at the lumbar spine and hip over the 11 months of the study, tracked along the time course seen in the postmenopausal women studied by Neer et al. (9). Although fractures could not be assessed during the short 11-month trial, they were assessed in a follow-up observational period of 30 months. 279 men from the original cohort had lateral thoracic and lumbar spine X-rays 18 months after treatment was stopped. In the combined teriparatide treatment groups $(20 \mu \mathrm{g}$ and $40 \mu \mathrm{g})$, the risk of vertebral fracture was reduced by $51 \%(p=0.07)$. Significant reductions were seen in the combined group as compared to placebo when only moderate or severe fractures were considered (6.8\% vs. $1.1 \%$; $<<0.02)$ (18). As was the case in the observational follow-up period in postmenopausal women, a substantial number of male study subjects in all groups $(25-30 \%)$ reported use of antiresorptive therapy during the follow-up period. Men treated with placebo utilized antiresorptive therapy to a greater extent than those who were treated with either dose of teriparatide (36\% vs. $25 \%)$.

\section{SEQUENTIAL AND COMBINATION THERAPY WITH TERIPARATIDE AND AN ANTIRESORPTIVE AGENT}

\section{Previous use of an antiresorptive}

Many patients who are considered candidates for teriparatide have previously been treated with bisphosphonates or other antiresorptives. Cosman et al. treated postmenopausal women, previously given estrogen for at least 1 year, with teriparatide (19). Increases in vertebral BMD began with no delay and increased in a linear fashion during the entire 3-year study. Ettinger et al. studied the influence of 2 other antiresorptives, raloxifene or alendronate, prior to treatment with teriparatide (20). 59 postmenopausal women with $\mathrm{T}$ scores $\leq-2.0$ had been treated for an average of 28 months either with raloxifene or alendronate. Although this was not a prospective clinical trial, in most respects subjects were well matched in terms of age, BMI, and T-scores. Similar to the study of Lindsay et al. for estrogen, raloxifene did not impede the effects of teriparatide to increase BMD rapidly and linearly. In contrast, alendronate was associated with a 6month delay before BMD in the lumbar spine began to increase. After 18 months, lumbar spine BMD increased by $10.2 \%$ in the prior raloxifene-treated group compared to only $4.1 \%$ in the prior-alendronate treated subjects $(\mathrm{p}<0.05)$. The alendronate-treated group showed an initial decline in hip BMD at 6 months but at 18 months, mean total hip BMD was not different from baseline. During teriparatide treatment, bone markers in prior alendronate patients increased later and peaked at about $1 / 3$ lower levels as compared to prior raloxifene-treated patients.

These results imply that the potency of the antiresorptive to control bone turnover can determine the early response to teriparatide. Cosman et al. have helped to refine this point in a study of teriparatide in postmenopausal women who also had previously received alendronate for the same period of time (21). In contrast to the study of Ettinger et al., their subjects responded to teriparatide with rapid increases in BMD. To account for these differences, it is noteworthy that the baseline bone turnover markers prior to the initiation of teriparatide therapy were markedly different in the 2 studies. In the study by Ettinger et al., bone turnover markers were almost completely suppressed. In comparison, in the study of Cosman et al., bone turnover markers were less suppressed and more in the range that one tends to find in subjects after alendronate therapy. Therefore, it is distinctly possible that it is not so much the specific antiresorptive used prior to teriparatide that dictates the subsequent densitometric response but rather the extent to which bone turnover is reduced. To support this idea, the response to teriparatide has been shown to be a function of the level of baseline bone turnover in subjects not previously treated with any therapy for osteoporosis: the higher the level of turnover, the more robust the densitometric response to teriparatide (16). This may seem counterintuitive, in that teriparatide stimulates bone formation and might be expected to have a greater effect in those with low bone turnover. This may relate to the need for active osteoblasts, primed osteoblasts, or progenitor osteoblast cells that are more receptive to the effects of teriparatide in a high turnover state.

\section{Concurrent use of anabolic and antiresorptive therapy}

It is attractive to consider combination therapy with an antiresorptive and PTH as potentially more beneficial than monotherapy given that their mechanisms of action are quite different from each other. If bone 
resorption is being inhibited (antiresorptive) while bone formation is being stimulated (anabolic), combination therapy might give better results than with either agent alone. Despite the intuitive appeal of this reasoning, important data to the contrary have been provided by Black et al. (22) and by Finkelstein et al. (23). These 2 groups independently completed trials using a form of PTH alone, alendronate alone, or the combination of a PTH form and alendronate. Black et al. studied postmenopausal women with $100 \mu \mathrm{g}$ of $\mathrm{PTH}(1-84)$. The study of Finkelstein et al. involved men treated with 40 $\mu \mathrm{g}$ of teriparatide. Both studies utilized DXA and QCT to measure areal or volumetric BMD respectively. With either measurement, monotherapy with PTH exceeded densitometric gains with combination therapy or alendronate alone at the lumbar spine. Measurement of trabecular bone by QCT, in fact, showed that combination therapy was associated with substantially smaller increases in BMD than monotherapy with PTH (figure 2). Bone turnover markers followed the expected course for anabolic (increases) or antiresorptive (decreases) therapy alone. However for combination therapy, bone markers followed the course of alendronate, not PTH therapy, with reductions in bone formation and bone resorption markers. This suggests that the impaired response to combination therapy, in comparison to PTH alone, might be due to the dominating effects of the antiresorptive agent on bone dynamics when both drugs are used together.
In a short 6-month clinical trial, Deal et al. have reported that the combination of teriparatide and raloxifene may have more beneficial effects than monotherapy with teriparatide in postmenopausal osteoporosis (24). Bone formation markers increased similarly in both groups. Bone resorption markers, however, were reduced in the combination group. BMD increased to a similar extent in the lumbar spine and femoral neck in both groups, but the increase in total hip BMD was significantly greater in subjects treated with both teriparatide and raloxifene.

\section{Consequences of discontinuing anabolic therapy with PTH}

Teriparatide is approved in most countries for a treatment period of 18-24 months. There are obvious concerns regarding the consequences of discontinuing therapy following this relatively short period of time. Some a priori concerns relate to the fact that new bone matrix is not fully mineralized following PTH therapy. Therefore, this new bone matrix could be at risk for resorption if a period of consolidation with an antiresorptive is not used (25).

Published data addressing this concern were initially based on observational trials $(22,40-42)$. These studies, using either bisphosphonate $(12,26,27)$ or estrogen $(28,29)$ therapy following PTH, suggested that antiresorptive treatment may be necessary to maintain densitometric gains achieved during PTH

\section{Changes in Trabecular BMD by QCT}

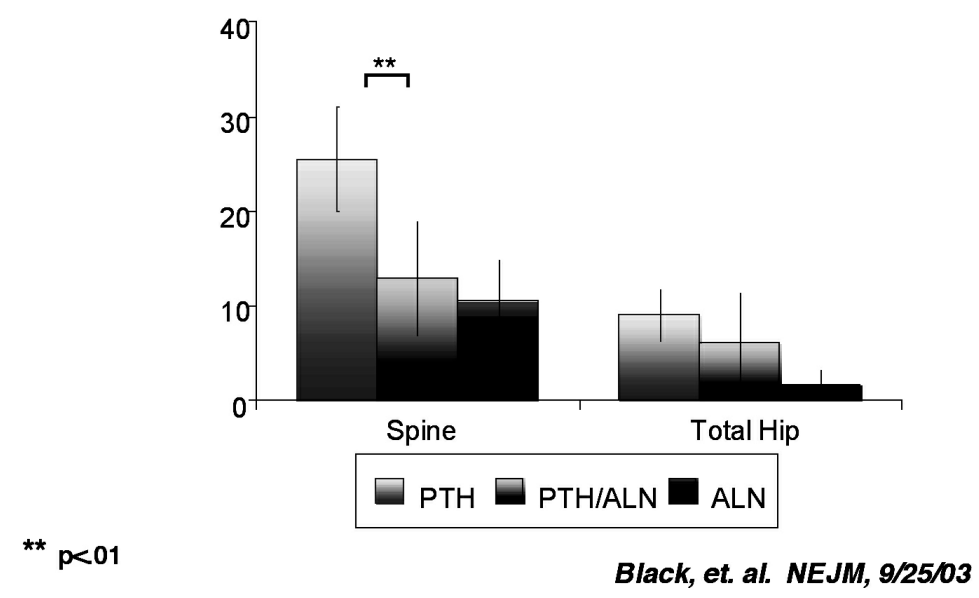

Figure 2. The effect of combination therapy with $\mathrm{PTH}(1-84)$ and alendronate on bone density of the lumbar spine. The use of monotherapy with $\mathrm{PTH}(1-84)$ is clearly superior in increasing lumbar spine BMD by QCT than combination therapy or monotherapy with alendronate. (Reprinted with permission from (22)) 
administration. With a stronger experimental design, the PaTH study has provided prospective data in a rigorously controlled, blinded fashion to address this issue (30). Postmenopausal women who had received PTH(1-84) for 12 months were randomly assigned to an additional 12 months of therapy with $10 \mathrm{mg}$ of alendronate daily or placebo. In subjects who received alendronate, there was a further $4.9 \%$ gain in lumbar spine BMD while those who received placebo experienced a substantial decline. By QCT analysis, the net increase over 24 months in lumbar spine BMD among those treated with alendronate after $\mathrm{PTH}(1-84)$ was $30 \%$. In those who received placebo after PTH(1-84), the net change in bone density was only $13 \%$. There were similar dramatic differences in hip BMD when those who followed PTH with alendronate were compared to those who were treated with placebo (13\% vs. $5 \%$ ). The results of this study establish the importance of following PTH or teriparatide therapy with an antiresorptive.

Fracture efficacy was reported in the 30-month observational cohort following the trial of Neer et al. (12). Subjects were given the option of switching to a bisphosphonate or not taking any further medications following teriparatide. A majority $(60 \%)$ was treated with antiresorptive therapy after PTH discontinuation. Gains in bone density were maintained in those who chose to begin antiresorptive therapy immediately after teriparatide. Reductions in BMD were progressive throughout the 30 -month observational period in subjects who elected not to follow teriparatide with any therapy. In a group who did not begin antiresorptive therapy until 6 months after teriparatide discontinuation, major reductions in BMD were seen during these first 6 months but no further reductions were observed after antiresorptive initiation (26). Despite these densitometric data, the effect of previous therapy with teriparatide and/or subsequent therapy with a bisphosphonate on fracture prevention persisted for as long as 31 months after teriparatide discontinuation. Nonvertebral fragility fractures were reported by proportionately fewer women previously treated with PTH (with or without a bisphosphonate) as compared with those treated with placebo (with or without a bisphosphonate; $\mathrm{p}<0.03$ ). In a logistic regression model, bisphosphonate use for 12 months or longer was said to add little to overall risk reduction of new vertebral fractures in this post-treatment period. However, it is hard to be sure of this conclusion, as the data were not actually separately analyzed into those who did or did not follow teriparatide treatment with an antiresorptive. Also, the above findings were in an observational study in which participants self-selected for the use of antiresorptive therapy after PTH treatment, making the results even more difficult to interpret. One might anticipate a residual but transient protection against fracture after PTH treatment without follow-up antiresorptive therapy, which could wane over time (45). Additional studies are needed to address fracture outcomes specifically. However, based particularly on the PaTH trial, the importance of following PTH or teriparatide therapy with an antiresorptive to maintain increases in bone mass is clear.

\section{Safety of PTH}

Overall, PTH is well tolerated. A toxicity that appears to be unique to animals and not applicable to human subjects is osteosarcoma. The development of osteosarcoma has been seen only in rats that have been given very high doses of either teriparatide or $\mathrm{PTH}(1-$ 84 ) for prolonged periods of time (31). It is unlikely that this animal toxicity is related to human skeletal physiology $(32,33)$, but in the United States there is a warning included in the labeling instructions. Tashiian and Gagel have recently summarized our current knowledge of this issue (new reference).

\section{PTH and future considerations}

In the future, PTH may be modified for easier and more targeted delivery. Parathyroid hormone-related protein (PTHrP) has also been studied as an anabolic skeletal agent. In a small sample of postmenopausal women, subcutaneous administration of PTHrP resulted in a $4.7 \%$ increase in lumbar spine density after only 3 months of treatment (34). Less frequent administration of PTH, such as once weekly, might also be an effective treatment option (35). Cosman et al. have reported on the use of cyclical 3-month courses of teriparatide against a backdrop of continued alendronate use (21). In comparison to regular, uninterrupted teriparatide use, the cyclic administration of teriparatide was associated with similar densitometric gains. Of further interest was the observation that with sequential 3-month cycles of teriparatide, bone formation markers that fell quickly when teriparatide was stopped, were stimulated to the same degree with each cycle. On the other hand, bone resorption markers showed smaller increases with successive cycles. This observation gives credence to the idea that the anabolic window is actually expanded when teriparatide is used in this context $(35,36)$. Most recently, Cosman et al. have shown that during long-term alendronate therapy, a rechallenge with PTH after 12 months off PTH increases bone formation, bone resorption and 
BMD to a similar extent as during the first course of PTH administration (37). These data suggest that a future paradigm might be a second course of PTH given 12 months after a first course of therapy in patients who remain at high fracture risk. Apart from forms and ways to administer exogenous PTH, Gowen et al. described an oral calcilytic molecule that antagonizes the parathyroid cell calcium receptor, thus stimulating the endogenous release of PTH (38). This approach could represent a novel endogenous delivery system for intermittent PTH administration.

\section{Strontium ranelate}

Animal data with strontium ranelate suggest this compound can both promote bone formation and inhibit bone resorption (39). The exact cellular mechanism of action of strontium ranelate remains unclear. The regulation of bone cell differentiation, namely stimulation of osteoblast proliferation and inhibition of osteoclast formation, and activation of the calcium-sensing receptor have been proposed as possible mechanisms $(39,40)$. It has also been suggested that there is a cation-sensing mechanism distinct from the calciumsensing receptor that responds to strontium in osteoblasts (41).

Clinical trials support the use of strontium ranelate as a treatment for postmenopausal osteoporosis $(42-44)$. Two recent studies, the Spinal Osteoporosis Therapeutic Intervention (SOTI) (43) and the Treatment of Peripheral Osteoporosis (TROPOS) (44) trials have shown that strontium ranelate reduces vertebral and nonvertebral fractures respectively. In the SOTI trial, 1,649 postmenopausal women with osteoporosis and at least one vertebral fracture were randomized to receive either 2 grams of strontium ranelate per day or placebo for 3 years. Treatment increased lumbar spine and femoral neck BMD, but the true BMD increase is difficult to interpret, even with corrective algorithms. This is because strontium has an atomic number greater than calcium which will weaken $\mathrm{x}$-ray penetration and result in an over-estimation of measured bone mineral density (69). Certain$\mathrm{ly}$, the incorporation of the strontium ion into bone is also causing an increase in bone density per se. After making adjustments for the effect of strontium, lumbar spine BMD increased by $6.8 \%$ after 3 years. Strontium ranelate reduced vertebral fractures by $49 \%$ following the first year of treatment and by $41 \%$ at the end of the 3 -year study period $(\mathrm{p}<0.001)$. Increases in bone formation markers and decreases in bone resorption markers were also observed with strontium treatment, consistent with the idea that the drug both pro- motes bone formation and inhibits bone resorption. The TROPOS trial, designed in parallel with the SOTI trial, was conducted to determine strontium's effects on nonvertebral fractures. In this study, 5,091 postmenopausal women with osteoporosis were randomized to either 2 grams/day of strontium ranelate or placebo. The relative risk of all nonvertebral fractures was reduced by $16 \%$ at 3 years $(p=0.04)$. In a subset of women at high risk for hip fracture (age $>74$ years, BMD $\mathrm{T}$ score $\leq-3)$, the risk of hip fracture was reduced by $36 \%(\mathrm{p}=0.046)$. The incidence of vertebral fractures also decreased in these subjects with a $39 \%$ risk reduction overall and a $45 \%$ risk reduction in the subgroup without prevalent vertebral fractures. Strontium ranelate was well tolerated in both trials with nausea and diarrhea occurring more frequently only during the first three months of therapy. Interestingly, slight reductions in PTH and calcium levels and a slight increase in phosphorus concentrations were observed in the strontium group as compared to placebo. These changes were of no clinical consequence but would be consistent with activation of the calciumsensing receptor by strontium (44).

\section{GROWTH HORMONE AND INSULIN-LIKE GROWTH FACTOR}

The rationale for considering GH and IGF-1 as potential anabolic agents is that both are critical for the acquisition and maintenance of bone mass. Particularly in men, GH and IGF-1 stimulate periosteal apposition, so it is logical to expect both might be effective in human subjects. An added theoretical advantage is salutary effects on muscle strength and coordination, leading potentially to a reduction in falls and fracture rates.

\section{Growth hormone}

Most of the studies utilizing GH, however, have been disappointing. Changes in bone mass are minimal in both men $(45)$ and women $(46,47)$. The lack of a beneficial effect with GH on bone mass could be due to the concomitant activation of bone resorption along with formation, so that a net gain does not occur $(47,48)$. Another explanation for a lack of effect could be the relatively short, one year, duration of many of these studies. Recent evidence suggested a delayed and what was ultimately a positive effect of $\mathrm{GH}$ on bone. In a double-blind, randomized, placebo-controlled trial, 80 postmenopausal women with osteoporosis on estrogen replacement therapy were administered either placebo, GH $1.0 \mathrm{U} /$ day, or $2.5 \mathrm{U} /$ day for 18 months 
(49). Women in both treatment groups continued GH for an additional 18 months. Although there were no significant differences between groups after 3 years, at 4 years, the higher dose of $\mathrm{GH}$ resulted in a $14 \%$ increase in lumbar spine bone mineral content. These unexpected results conflict with most data on effective osteoporosis therapies in which major increases in bone mass are typically limited to the first three years of therapy. One possible explanation for the "catchup" bone gain after $\mathrm{GH}$ withdrawal might be that the drop in IGF-1 halts GH-stimulated resorption but allows osteoblastic stimulation to persist (50).

\section{IGF-1}

IGF-1 promotes chondrocyte and osteoblast differentiation and growth $(51)$. It is also a pivotal factor in the coupling of bone turnover, as it is stored in the skeletal matrix and released during bone resorption (5l). When the IGF-1 receptor in bone is knocked out in mice, decreased bone formation and suppressed mineralization ensue (52). Two prospective clinical studies have suggested that low levels of IGF-1 are associated with a greater risk of spine and hip fractures $(53,54)$.

Data on IGF-1 therapy exist for postmenopausal and young women. IGF-1 theoretically is more appealing than $\mathrm{GH}$, because it stimulates bone formation more directly. When elderly women were administered low doses of rhIGF-1, markers of bone formation were differentially stimulated with only a minimal increase in bone resorption (55). Similarly, markers of bone formation increased in short-term trials of young women with anorexia nervosa administered IGF-1 alone (56) or in combination with risedronate (18). A major drawback to the development of IGF-1 as a therapy for osteoporosis is its ubiquitous effect on many organ systems. Similar to $\mathrm{GH}$, potential serious adverse effects could surface with its chronic use.

\section{FUTURE ANABOLIC THERAPIES}

Other promising anabolic agents are on the horizon. For example, compounds that might augment the recently identified wnt-signaling pathway, such as inhibitors of sclerostin (57), could yield potentially powerful anabolic effects in the years to come.

\section{CONCLUSIONS}

Although antiresorptives remain the mainstay of osteoporosis treatment, the advent of anabolic skeletal agents is changing our approach to therapy. Of the anabolic agents discussed above, parathyroid hormone has clearly emerged as the most promising current treatment. For the first time, a drug is available that not only improves bone density, features of bone turnover, and reduces fracture incidence, but also significantly improves microarchitectural and geometric properties of bone. These changes in bone quality induced by teriparatide are attractive considering the goal of therapy for osteoporosis, namely to improve the basic underlying abnormalities that give rise to skeletal fragility. Recent studies have given insight on the optimal use of this agent, including the importance of subsequent antiresorptive treatment to preserve gains in bone mass incurred during PTH therapy. With the development of additional and more costeffective therapies, the use of anabolic agents will likely increase in the years to come.

\section{ACKNOWLEDGEMENTS}

This project was funded, in part, by NIH grant NIDDK 32333.

\section{REFERENCES}

1. Hodsman AB, Bauer DC, Dempster D, Dian L, Hanley DA, Harris ST, et al. Parathyroid hormone and teriparatide for the treatment of Osteoporosis: A review of the evidence and suggested guidelines for its use. Endocr Rev 2005;26(5):688-703

2. Dempster DW, Parisien $M$, Silverberg $S J$, Liang $X G$, Schnitzer M, Shen V, et al. On the mechanism of cancellous bone preservation in postmenopausal women with mild primary hyperparathyroidism. J Clin Endocrinol Metab 1999;84(5):1562-6.

3. Rubin M, Bilezikian J. The anabolic effects of parathyroid hormone therapy. Clin Geriat Med 2002; 19:415-32.

4. Jiang $Y$, Zhao JJ, Mitlak BH, Wang O, Genant HK, Eriksen EF. Recombinant human parathyroid hormone (1-34) (teriparatide) improves both cortical and cancellous bone structure. J Bone Miner Res 2003; 18(1 1): 1932-41

5. Burr DB, Hirano T, Turner $\mathrm{CH}$, Hotchkiss $\mathrm{C}$, Brommage $\mathrm{R}$, Hock JM. Intermittently administered human parathyroid hormone(1-34) treatment increases intracortical bone turnover and porosity without reducing bone strength in the humerus of ovariectomized cynomolgus monkeys. J Bone Miner Res 2001;16(1):157-65.

6. Parfitt AM. Parathyroid hormone and periosteal bone expansion. J Bone Miner Res 2002;17(10):1741-3.

7. Zanchetta JR, Bogado CE, Ferretti JL, Wang O, Wilson $M G$, Sato $M$, et al. Effects of teriparatide (recombinant human parathyroid hormone (1-34)) on cortical bone in postmenopausal women with osteoporosis. J Bone Miner Res 2003; 18(3):539-43. 
8. Lindsay R, Silverman SL, Cooper C, Hanley DA, Barton I, Broy SB, et al. Risk of new vertebral fracture in the year following a fracture. JAMA 2001;285(3):320-3.

9. Neer RM, Arnaud CD, Zanchetta JR, Prince R, Gaich GA, Reginster JY, et al. Effect of parathyroid hormone (1-34) on fractures and bone mineral density in postmenopausal women with osteoporosis. N Engl J Med 2001;344(19):1434-41.

10. Gallagher JC, Genant HK, Crans GG, Vargas SJ, Krege $\mathrm{JH}$. Teriparatide reduces the fracture risk associated with increasing number and severity of osteoporotic fractures. J Clin Endocrinol Metab 2005;90(3):1583-7.

11. Marcus R, Wang $O$, Satterwhite J, Mitlak B. The skeletal response to teriparatide is largely independent of age, initial bone mineral density, and prevalent vertebral fractures in postmenopausal women with osteoporosis. J Bone Miner Res 2003; 18(1):18-23.

12. Prince $R$, Sipos A, Hossain A, Syversen U, Ish-Shalom $S$, Marcinowska $E$, et al. Sustained nonvertebral fragility fracture risk reduction after discontinuation of teriparatide treatment. J Bone Miner Res 2005;20(9):1507-13.

13. Hodsman AB, Hanley DA, Ettinger MP, Bolognese MA, Fox J, Metcalfe AJ, et al. Efficacy and safety of human parathyroid hormone-(1-84) in increasing bone mineral density in postmenopausal osteoporosis. J Clin Endocrinol Metab 2003;88(1 1):5212-20.

14. Fox J, Miller MA, Recker RR, Bare SP, Smith SY, Moreau I. Treatment of postmenopausal osteoporotic women with parathyroid hormone 1-84 for 18 months increases cancellous bone formation and improves cancellous architecture: A study of iliac crest biopsies using histomorphometry and micro computed tomography. J Musculoskelet Neuronal Interact 2005;5(4):356-7.

15. Ettinger M, Greenspan S, Marriott TB, Hanley DA Zanchetta JR, Bone HG 3rd, et al. PTH(1-84) prevents first vertebral fracture in postmenopausal women with osteoporosis: results from the TOP study. American College of Rheumatology Annual Meeting, 2004. p. L17.

16. Kurland ES, Cosman F, McMahon DJ, Rosen CJ, Lindsay $\mathrm{R}$, Bilezikian JP. Parathyroid hormone as a therapy for idiopathic osteoporosis in men: effects on bone mineral density and bone markers. J Clin Endocrinol Metab 2000;85(9):3069-76.

17. Orwoll ES, Scheele WH, Paul S, Adami S, Syversen U, DiezPerez A, et al. The effect of teriparatide (human parathyroid hormone (1-34)) therapy on bone density in men with osteoporosis. J Bone Miner Res 2003; 18(1):9-17.

18. Kaufman JM, Orwoll E, Goemaere S, San Martin J, Hossain A, Dalsky GP, et al. Teriparatide effects on vertebral fractures and bone mineral density in men with osteoporosis: treatment and discontinuation of therapy. Osteoporosis Int 2005; 16(5):510-6.

19. Cosman F, Nieves J, Woelfert L, Formica C, Gordon S, Shen $V$, et al. Parathyroid hormone added to established hormone therapy: effects on vertebral fracture and maintenance of bone mass after parathyroid hormone withdrawal. J Bone Miner Res 2001;16(5):925-31.

20. Ettinger B, San Martin J, Crans G, Pavo I. Differential effects of teriparatide on BMD after treatment with raloxifene or alendronate. J Bone Miner Res 2004; 19(5):745-51.
21. Cosman F, Nieves J, Zion M, Woelfert L, Luckey M, Lindsay R. Daily and cyclic parathyroid hormone in women receiving alendroante. N Eng J Med 2005;353:566-75.

22. Black DM, Greenspan SL, Ensrud KE, Palermo L, McGowan JA, Lang TF, et al. The effects of parathyroid hormone and alendronate alone or in combination in postmenopausal osteoporosis. N Engl J Med 2003:349(13): 1207-15.

23. Finkelstein JS, Hayes A, Hunzelman JL, Wyland JJ, Lee H, Neer RM. The effects of parathyroid hormone, alendronate, or both in men with osteoporosis. N Engl J Med 2003;349(13): 1216-26.

24. Deal C, Omizo M, Schwartz EN, Eriksen EF, Cantor P, Wang J, et al. Combination teriparatide and raloxifene therapy for postmenopausal osteoporosis: results from a 6-month double-blind placebo-controlled trial. J Bone Miner Res 2005;20(11):1905-11.

25. Misof BM, Roschger P, Cosman F, Kurland ES, Tesch W, Messmer $P$, et al. Effects of intermittent parathyroid hormone administration on bone mineralization density in iliac crest biopsies from patients with Osteoporosis: A paired study before and after treatment. J Clin Endocrinol Metab 2003;88(3):1150-6.

26. Lindsay R, Scheele WH, Neer R, Pohl G, Adami S, Mautalen $\mathrm{C}$, et al. Sustained vertebral fracture risk reduction after withdrawal of teriparatide in postmenopausal women with osteoporosis. Arch Intern Med 2004; 164(18):2024-30.

27. Kurland ES, Heller SL, Diamond B, McMahon DJ, Cosman F, Bilezikian JP. The importance of bisphosphonate therapy in maintaining bone mass in men after therapy with teriparatide (human parathyroid hormone(1-34)). Osteoporosis Int 2004; 15(12):992-7.

28. Lindsay R, Nieves J, Formica C, Henneman E, Woelfert L, Shen $V$, et al. Randomised controlled study of effect of parathyroid hormone on vertebral-bone mass and fracture incidence among postmenopausal women on oestrogen with osteoporosis. Lancet 1997;350(9077):550-5.

29. Lane NE, Sanchez S, Modin GW, Genant HK, Pierini E, Arnaud $C D$. Bone mass continues to increase at the hip after parathyroid hormone treatment is discontinued in glucocorticoid-induced osteoporosis: results of a randomized controlled clinical trial. J Bone Miner Res 2000; 15(5):944-51.

30. Black DM, Bilezikian JP, Ensrud KE, Greenspan SL, Palermo L, Hue $\mathrm{T}$, et al. One year of alendronate after one year of parathyroid hormone (1-84) for osteoporosis. $\mathbf{N}$ Engl J Med 2005;353(6):555-65.

31. Vahle JL, Long GG, Sandusky G, Westmore M, Ma YL, Sato $\mathrm{M}$. Bone neoplasms in F344 rats given teriparatide (rhPTH(1-34)) are dependent on duration of treatment and dose. Toxicol Pathol 2004;32(4):426-38.

32. Jimenez C, Kim W, Al Sagier F, El Naggar A, Sellin R, Berry $D$, et al. Primary hyperparathyroidism and osteosarcoma: examination of a large osteosarcoma cohort identifies unique characteristics. J Bone Miner Res 2003; 18(suppl. 2):LB6.

33. Tashijan AH Jr., Gagel RF. Teriparatide (human PTH(134)): 2.5 years of experience on the use and safety of the drug for the treatment of osteoporosis. J Bone Min Res 2006:21:354-65. 
34. Horwitz MJ, Tedesco MB, Gundberg C, Garcia-Ocana A, Stewart AF. Short-term, high-dose parathyroid hormonerelated protein as a skeletal anabolic agent for the treatment of postmenopausal osteoporosis. J Clin Endocrinol Metab 2003;88(2):569-75.

35. Black DM, Rosen CJ. Parsimony with PTH: Is a single weekly injection of PTH superior to a larger cumulative dose given daily? J Bone Miner Res 2002;17(suppl. 1):SA367.

36. Heaney RP, Recker RR. Combination and sequential therapy for osteoporosis. N Engl J Med 2005;353(6):6245.

37. Cosman F, Nieves JW, Zion M, Barbuto N, Lindsay R. Effects of PTH rechallenge 1 year after the first PTH course in patients on long-term alendronate. 27th Annual Meeting of the American Society for Bone and Mineral Research, Nashville, Tennessee, 2005. Presentation Number 1079.

38. Gowen M, Stroup GB, Dodds RA, James IE, Votta JB, Smith BR, et al. Antagonizing the parathyroid calcium receptor stimulates parathyroid hormone secretion and bone formation in osteopenic rats. J Clin Invest 2000; 105(11):1595-604.

39. Marie PJ, Ammann P, Boivin G, Rey C. Mechanisms of action and therapeutic potential of strontium in bone. Calcif Tissue Int 2001;69(3):121-9,

40. Brown EM. Is the calcium receptor a molecular target for the actions of strontium on bone? Osteoporos Int 2003; 14(suppl. 3):S25-34

41. Pi M, Quarles LD. A novel cation-sensing mechanism in osteoblasts is a molecular target for strontium. J Bone Miner Res 2004; 19(5):862-9.

42. Meunier PJ, Slosman DO, Delmas PD, Sebert JL, Brandi $\mathrm{ML}$, Albanese $\mathrm{C}$, et al. Strontium ranelate: dose-dependent effects in established postmenopausal vertebral osteoporosis-a 2-year randomized placebo controlled trial. J Clin Endocrinol Metab 2002;87(5):2060-6.

43. Meunier PJ, Roux C, Seeman E, Ortolani S, Badurski JE, Spector TD, et al. The effects of strontium ranelate on the risk of vertebral fracture in women with postmenopausal osteoporosis. N Engl J Med 2004;350(5):459-68.

44. Reginster JY, Seeman E, De Vernejoul MC, Adami S, Compston J, Phenekos $C$, et al. Strontium ranelate reduces the risk of nonvertebral fractures in postmenopausal women with osteoporosis: Treatment of Peripheral Osteoporosis (TROPOS) study. J Clin Endocrinol Metab 2005;90(5):2816-22.

45. Rudman D, Feller AG, Nagraj HS, Gergans GA, Lalitha PY, Goldberg AF, et al. Effects of human growth hormone in men over 60 years old. N Engl J Med 1990;323(1): 1-6.

46. Holloway L, Butterfield G, Hintz RL, Gesundheit N, Marcus R. Effects of recombinant human growth hormone on metabolic indices, body composition, and bone turnover in healthy elderly women. J Clin Endocrinol Metab 1994;79(2):470-9.
47. Donahue LR, Rosen CJ. Growth Hormone and InsulinLike Growth Factor I as therapeutic modalities for agerelated Osteoporosis. In: Rosen CJ, Glowacki J, Bilezikian JP. The aging skeleton. San Diego: Academic Press, 1999. pp. 579-84.

48. Ackert-Bicknell C, Rubin J, Zhu L, Fan X, Murphy T, Nanes $M$, et al. IGF-I Acts as a coupling factor for bone remodeling by regulating osteoprotegerin and RANK ligand in vitro and osteoprotogerin in vivo. 84 $4^{\text {th }}$ Annual Meeting of the Endocrine Society, San Francisco, CA, 2002. pp. 3366.

49. Landin-Wilhelmsen K, Nilsson A, Bosaeus I, Bengtsson BA. Growth hormone increases bone mineral content in postmenopausal osteoporosis: a randomized placebocontrolled trial. J Bone Miner Res 2003; 18(3):393-405.

50. Rosen CJ, Wuster C. Growth hormone rising: did we quit too quickly? J Bone Miner Res 2003; 18(3):406-9.

51. Donahue L, Rosen CJ. IGFs and bone. The osteoporosis connection revisited. Proc Soc Exp Biol Med 1998;219:1-

52. Hurley MM, Okada Y, Sobue T, Zhang XZ, Xiao L, Tanaka $Y$, et al. The anabolic effect of parathyroid hormone is impaired in bones of Fgf2 null mice. J Bone Miner Metab 2002;17(suppl. 1):1061.

53. Sugimoto T, Nishiyama K, Kuribayashi F, Chihara K. Serum levels of insulin-like growth factor (IGF) I, IGF-binding protein (IGFBP)-2, and IGFBP-3 in osteoporotic patients with and without spinal fractures. J Bone Miner Res 1997; 12(8): 1272-9.

54. Bauer DC, Rosen CJ, Cauley J, Cummings SR. Low serum IGF-1 but not IGFBP-3 predicts hip and spine fracture: the study of osteoporotic fracture. J Bone Miner Res 1998:23:S561.

55. Ghiron LJ, Thompson JL, Holloway L, Hintz RL, Butterfield $G E$, Hoffman AR, et al. Effects of recombinant insulin-like growth factor-l and growth hormone on bone turnover in elderly women. J Bone Miner Res 1995; 10(12):1844-52.

56. Grinspoon S, Baum H, Lee K, Anderson E, Herzog D, Klibanski A. Effects of short-term recombinant human insulin-like growth factor I administration on bone turnover in osteopenic women with anorexia nervosa. J Clin Endocrinol Metab 1996;81(11):3864-70.

57. Ott SM. Sclerostin and Wnt signaling-the pathway to bone strength. J Clin Endocrinol Metab 2005:90(12):6741-3.

\section{Address for correspondence:}

John P. Bilezikian

Department of Medicine

College of Physicians and Surgeons

630 W. $168^{\text {th }}$ Street

New York, NY 10032

Fax: 212-305-6486

E-mail: jpb2@columbia.edu 